\title{
Bazı Maleik Anhidrit İçeren Kopolimerlerin Amin Yapılı İlaç Etken Maddeleri İle Türevlendirilmesi, Yapısal Karakterizasyonu ve Biyolojik Aktiviteleri
}

\author{
Gülderen KARAKUŞ
}

\section{ÖZET}

Poli(maleik anhidrit-ko-stiren) (MAST), poli(maleik anhidrit$k o$-vinil asetat) (MAVA), poli(maleik anhidrit-kometilmetakrilat) (MAMMA), poli(maleik anhidrit-ko-allil fenil eter) (MAAFE) ve poli(maleik anhidrit-alt-akrilik asit) (MAAA) kopolimerleri serbest radikal polimerizasyon tepkimesi ile sentezlendi. Kopolimerlerin amin $\left(-\mathrm{NH}_{2}\right)$ yap1l ilaç etken maddeleri ile modifikasyonu/türevlendirilmesi halka açılma tepkimesi ile yapıldı. Kopolimer ve kopolimer/ ilaç çiftlerinin yapısal karakterizasyonu Fourier Transform Infrared (FTIR) ve Nükleer Magnetik Rezonans ( $\left.{ }^{1} \mathrm{H}-\mathrm{NMR}\right)$ yöntemleriyle ile yapıldı. FTIR ve ${ }^{1} \mathrm{H}-\mathrm{NMR}$ spektrumları kopolimer ve ilaç etken maddesi arasındaki modifikasyon tepkimesini doğrulamaktadır. Sentezlenen konjugatların sağlıklı hücreler üzerine olan sitotoksik etkileri, birkaç kanser hücresi üzerine olan antiproliferatif etkileri ve birkaç bakteri üzerine olan antibakteriyel etkileri de in-vitro olarak araştırıldı. Ayrıca kullanılan bu farklı kopolimerlerin amin yapılı ilaç etken maddelerine olan ilgileri de karşılaştırılarak modifikasyon/türevlendirme için en uygun kopolimer MAVA olarak seçildi.

Anahtar Kelimeler: Kopolimer modifikasyonu, halka açılma tepkimesi, antiproliferatif etki, antibakteriyel etki, yapısal karakterizasyon.
Gülderen Karakuş

Cumhuriyet Üniversitesi, Eczacllı Fakültesi, Farmasötik Kimya Anabilim Dalı, Sivas 58140, Türkiye

Yazı Sorumlusu:

Gülderen KARAKUŞ

Tel: +90 $3462191010-3910$

Faks: +903462191634

E-mail: gulderen@cumhuriyet.edu.tr gulderenkarakus@gmail.com

\section{GíRiș}

Maleik anhidrit (MA), $\mathrm{C}_{4} \mathrm{H}_{2} \mathrm{O}_{3}$ genel formülüne sahip eşsiz bir elektron-alıcı monomerdir. MA içerikli kopolimerler serbest radikal polimerizasyon tepkimeleri ile başlatıcılar kullanılarak sentezlenmektedir. Polianhidritler olarak da bilinen MA kopolimerleri reaktif anhidrit halkası nedeniyle halka açılma tepkimeleri için oldukça elverişlidirler. Böylece su $\left(\mathrm{H}_{2} \mathrm{O}\right)$, alkol $(\mathrm{ROH})$, amin $\left(\mathrm{RNH}_{2}\right)$ ve amin türevleri gibi küçük mol kütleli moleküllerle modifikasyona uğrayabilirler. Bu özelliklerine ek olarak ekonomik olmaları da onları birçok alanda yaygın olarak kullanılabilir hale getirerek ticari olarak da artık ulaşılabilir haldedirler. Nanoparçacıklar için çözündürücü ajan olmalarının yanısıra, yüzey modifikasyonu, makromoleküler ilaç taşıyıcı sistemler, tanı amaçlı görüntüleme ajanları, implantlar, diğer uygulamalarıdır (1). MA üzerinde tekrarlanan oldukça 
reaktif anhidrit halkası nükleofilik bileşiklerin hidroksil $(-\mathrm{OH})$ ya da amino $\left(-\mathrm{NH}_{2}\right)$ gruplarına halka açılma tepkimesi ile bağlanarak ester/karboksilik asit ya da amid/ karboksilik asit yapılarının oluşmasına neden olur (2,3-5). Örneğin $\mathrm{ROH}$ genel formülüne sahip alkoller ile halka açılma tepkimesi;

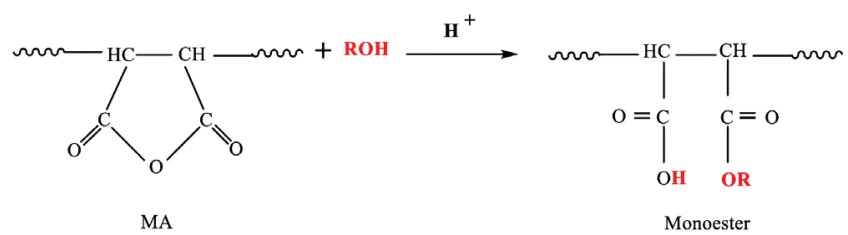

Şekil 1. MA içerikli kopolimerden elde edilen monoesterin kimyasal yapis1.

şeklinde gösterilirken, $\mathrm{RNH}_{2}$ genel formülüne sahip aminler ile halka açılma tepkimesi ise aşağıdaki gibi genelleştirilebilmektedir.

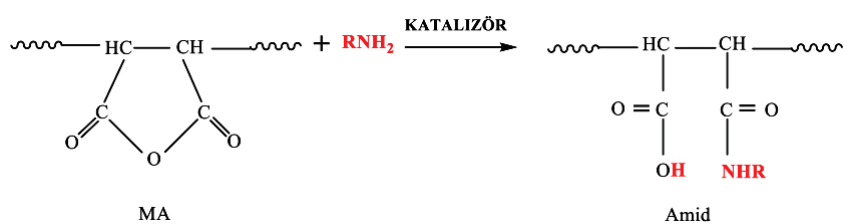

Şekil 2. MA içerikli kopolimerden elde edilen amidin kimyasal yapısı.

Helmut Ringsdorf, 1975 yılında kendi adiyla bilinen Ringsdorf modelini (Şekil 3) önererek polimer bazlı prodrug (ön ilaç) rasyonel dizaynı için ilk adımları atmıştır $(6,7)$.

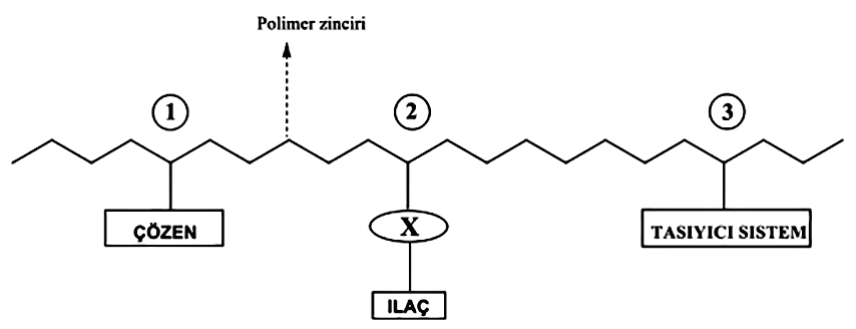

Şekil 3. Sentetik polimerik ilaçlar için Ringsdorf modeli.

Kopolimerlerle ilgili ilk biyolojik etki çalışması maleik anhidrit-divinil eter (DIVEMA) kopolimeri ile yapılmıştır (8). Bu kopolimer antikoagulan ve antienflamatuvar ajan olarak kullanıldığı gibi antiviral, antibakteriyel ve antifungal etkinliğe de sahiptir $(9,10)$. Ticari olarak pazarlanan en popüler kopolimer ise SMA olarak da bilinen poli(stiren- $k o$ maleik asit/anhidrit)'tir $(2,11)$.
Tablo 1. Kullanılan ilaç etken maddeleri ve kimyasal formülleri

İaç etken
maddesi
Prokainamid
hidroklorür

$\mathrm{Bu}$ çalışmada daha önce sentezlenen beş farklı maleik anhidrit içerikli kopolimerin amin türevi olan ilaç etken maddeleri ile halka açılma tepkimesi üzerinden modifikasyonu yapılmıştır. Burada asıl amaç hangi kopolimerin amin türevlerine daha yatkın olduğu ve elde edilen modifikasyon ürününün herhangi bir biyolojik etkiye sahip olup olmadı̆̆ıdır. Bu amaçla; poli(maleik anhidrit- 
Tablo 2. Kopolimerler için tepkime şartları

\begin{tabular}{|c|c|c|c|c|c|}
\hline $\begin{array}{l}\frac{1}{7} \\
\frac{1}{0}\end{array}$ & 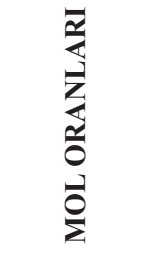 & 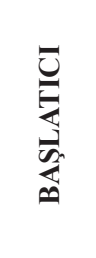 & 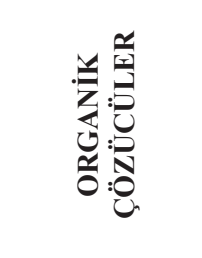 & 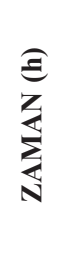 & 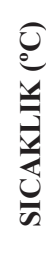 \\
\hline MAST & $\begin{array}{l}\text { MA:ST } \\
\sim(1: 1)\end{array}$ & AIBN & Benzen & 1 & 70 \\
\hline MAVA & $\begin{array}{c}\text { MA:VA } \\
\sim(1: 1)\end{array}$ & $\mathrm{BPO}$ & Metil etil keton & 24 & 80 \\
\hline MAMMA & $\begin{array}{c}\text { MA:MMA } \\
\sim(1: 1)\end{array}$ & $\mathrm{BPO}$ & Metil etil keton & 24 & 80 \\
\hline MAAFE & $\begin{array}{c}\text { MA:AFE } \\
\sim(1: 1)\end{array}$ & AIBN & Butil asetat & 1 & 70 \\
\hline MAAA & $\begin{array}{l}\text { MA:AA } \\
\sim(1: 1)\end{array}$ & $\mathrm{BPO}$ & p-dioksan & 8 & 70 \\
\hline
\end{tabular}

BPO: Benzoil peroksid, TEA: Trietilamin, MEK: Metiletil keton, DMF: Dimetilformamid.

Tablo 3. Kullanılan ilaç etken maddeleri ve kimyasal formülleri.

\begin{tabular}{|c|c|c|c|c|c|}
\hline 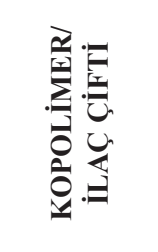 & 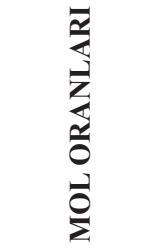 & 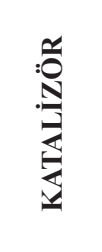 & نَّ & $\begin{array}{l}\hat{\Xi} \\
\vdots \\
\sum_{N}^{3}\end{array}$ & 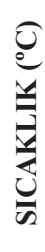 \\
\hline MAVA/NA & $(1: 1)$ & TEA & DMF & 24 & 70 \\
\hline MAST/PH & $(1: 1)$ & EDAC & ultra saf su & 48 & 60 \\
\hline MAVA/DX & $(1: 1)$ & EDAC & ultra saf su & 72 & 75 \\
\hline MAVA/HX & $(1: 1)$ & TEA & DMF & 50 & 70 \\
\hline MAVA/CF & $(1: 1)$ & TEA & DMF & $\begin{array}{c}2 \\
+ \\
48\end{array}$ & $\begin{array}{c}50 \\
+ \\
70\end{array}$ \\
\hline MAAA/AF & $\begin{array}{l}(1: 1) \text { ya da } \\
(1: 2)\end{array}$ & TEA & DMF & $\begin{array}{c}2 \\
+ \\
46\end{array}$ & $\begin{array}{l}50 \\
+ \\
70\end{array}$ \\
\hline MAVA/PT & $(1: 1)$ & - & $\mathrm{Su}+\mathrm{DMF}$ & 73 & 75 \\
\hline
\end{tabular}

BPO: Benzoil peroksid, TEA: Trietilamin, MEK: Metiletil keton, DMF: Dimetilformamid.

$k o$-stiren) (MAST), poli(maleik anhidrit-ko-vinil asetat) (MAVA), poli(maleik anhidrit-ko-metilmetakrilat) (MAMMA), poli(maleik anhidrit-ko-allil fenil eter) (MAAFE) ve poli(maleik anhidrit-alt-akrilik asit) (MAAA) kopolimerlerinin modifikasyonunda prokainamid hidroklorür $(\mathrm{PH})$, hidroksiüre $(\mathrm{HX})$, siterabin $(\mathrm{CF})$, cisplatin (PT), noradrenaline (NA), doksorubisin hidroklorür (DX), akriflavin (AF) ilaç etken maddeleri nükleofilik ajan olarak seçilmiştir. Bu ajanlardan NA vazokonstriktör, PH kardiyak anti-aritmik, AF topikal antiseptik, boya ve antikanser bir ilaç etken maddesi iken; DX, HX, CF ve PT antikanser ilaç etken maddeleridir. Bahsi geçen ilaç etken maddelerinin kimyasal formülleri Tablo 1'de verilmiştir.

\section{GEREÇ VE YÖNTEM}

Kimyasallar

Kopolimerlerin hazırlanmasında monomer olarak maleik anhidrit (MA), stiren (ST), vinil asetat (VA), metil metakrilat (MMA) ve allil fenil eter (AFE) (Merck, Schuchardt, Almanya), başlatıcı olarak benzoil peroksit (BPO) (Merck, Schuchardt, Almanya) ile azobisizobutironitril (AIBN) (Peaxnm, Rusya) kullanıldı. Kopolimerleşme tepkimeleri, benzen (Carlo-Erba, Strada Rivoltona, Rodano) ve etil metil keton (Merck, Darmstadt, Almanya) organik çözücülerinde gerçekleştirildi. Akrilik asit (AA) (Fluka, Almanya) ise kullanılmadan önce distile edildi. Kopolimerler, olası monomer artıklarından ve homopolimerleşmeden doğabilecek kopolimer dışındaki safsızlıklardan uzaklaştırıldı.

Kopolimer-ilaç etken madde çiftlerinin hazırlanmasında katalizör olarak trietilamin (TEA) ve $\mathrm{N}$-(3dimetilaminopropil)- $N$ '- etilkarbodiimid (EDAC) (Merck, Schuchardt, Germany) kullanıldı. Bu çiftler hazırlanırken TEA katalizörünün kullanıldı ğ 1 tepkimeler $N, N$ dimetilformamid (DMF) (Merck, Darmstadt, Germany) çözücüsünde, EDAC katalizörünün kullanıldığı tepkimeler ise su (Deva ilaç-İstanbul-Türkiye)-kopolimer karışımı şeklinde sodyum hidroksit ve hidroklorik asit (SigmaAldrich, St. Louis, USA) ile pH değerinin ayarlandı̆̆ 1 viskoz çözeltide gerçekleştirildi. Kopolimer-cisplatin kompleksi hazırlanırken diğer türevlendirme işlemlerinden farklı olarak gümüş nitrat, potasyum klorür ve nitrik asit (Sigma-Aldrich, St. Louis, USA) kullanıld1.

Kopolimer-ilaç etken madde çiftlerinin hazırlanmasında, cis-diaminoplatin II diklorür kristali (PT), hidroksiüre (HX), sitozin $\beta$-D-arabinofuranosid hidroklorür (CF), doksorubisin hidroklorür (DX), prokainamid hidroklorür $(\mathrm{PH})$, noradrenalin (NA) ve akriflavin (AF) (Sigma-Aldrich, St. Louis, USA) ilaç etken maddeleri kullanıldı. İlaç etken maddelerinin çözünmesi için çoğunlukla steril apirojen enjeksiyonluk distile su (Deva Pharma) ile nadiren tridistile su kullanildi. 


\section{Kopolimerlerin Sentezi}

Maleik anhidrit içeren 5 farklı kopolimer poli(maleik anhidrit-ko-stiren) (MAST), poli(maleik anhidrit-ko-vinil asetat) (MAVA), poli(maleik anhidrit-ko-metilmetakrilat) (MAMMA), poli(maleik anhidrit-ko-allil fenil eter) (MAAFE) ve poli(maleik anhidrit-alt-akrilik asit) (MAAA) sentezlenme koşulları kısaca Tablo 2'de özetlenmiştir (12).

\section{Kopolimer/İlaç Konjugatlarının Sentezi}

Tablo 2'de özetlenen kopolimerlerin sentez şartları ve elde edilen kopolimer/ilaç konjugatlarının; MAVA/NA, MAST/ PH, MAVA/DX, MAVA/HX, MAVA/CF, MAAA/AF ve MAVA/PT sentezlenme koşulları kısaca Tablo 3'de özetlenmiştir.

\section{Yapısal Karakterizasyon}

Kopolimer ve modifikasyon ürünleri KBr pelletleri (100 mg $\mathrm{KBr}$ içinde $2 \mathrm{mg}$ örnek) şeklinde FTIR spektrofotometresinde (MATTSON 1000 Unicam, USA) 400-4000 $\mathrm{cm}^{-1}$ dalga sayısı aralığında, $4 \mathrm{~cm}^{-1}$ aralıklarla yapıldı. Nukleer Magnetik Rezonans, ${ }^{1} \mathrm{H}-\mathrm{NMR}$ analizi ise $400 \mathrm{MHz}$ 'de (Bruker Avance III, Karlsruhe, Germany) 6 mg kopolimer ya da modifikasyon ürününün, $0.8 \mathrm{~mL}$ dimetil sülfoksid (DMSO) içinde hazırlanması ile yapıldı. Bu karakterizasyon çalışmaları Teknoloji Araştırma Uygulama Merkezi’nde (Erciyes Üniversitesi, Kayseri, Türkiye) yapıldı.

\section{Antitumor, Sitotoksik ve Antimikrobiyal Aktivite}

Kopolimer-ilaç etken madde çiftlerinin bazılarının antitümör etkileri in-vitro olarak HeLa (insan rahim tümör hücresi) ve C6 (sıçan beyin tümör hücresi) üzerinde hücre kültürü yapılarak BrdU cell ELISA yöntemiyle tespit edildi. $\mathrm{Bu}$ işlemler sırasında Dulbecco'nun modifiye eagle medyumu (DMEM), Dulbecco'nun fosfat tampon tuzu (D-PBS), tripsin-EDTA (Sigma-Aldrich, St. Louis, USA) ve besiyeri kullanıldı. Sitotoksisite testleri için hem fare fibroblast hücre serisi (L929) ve laktat dehidrogenaz (LDH) testi kullanıldı. Antimikrobiyal duyarlılık testi sadece MAAA/AF konjugatına Kirby Bauer Disk Difüzyon yöntemi Mueller-Hinton Agar kullanılarak Enterecoccus faecium, Enterohaemorrhagic Escherichia coli (EHEC), Staphylococcus aureus and Listeria monocytogenes suşları üzerinde test edilerek yapıldı.

\section{BULGULAR ve TARTISMA}

\section{Yapısal Karakterizasyon}

Daha önceki çalışmalarımızda sentezlediğimiz kopolimer/ ilaç konjugatları için elde edilen FTIR ve NMR $\left({ }^{1} \mathrm{H}-\mathrm{NMR}\right.$ ve ${ }^{13} \mathrm{C}$-NMR) spektrum sonuçları kopolimer ve ilaç etken maddesi arasındaki konjugasyon tepkimesini hem desteklemekte hem de doğrulamaktadır (13-15). Ayrıca FTIR ve NMR sonuçlarına göre seçilen 5 kopolimerden MAVA kopolimeri konjugasyon için en uygun olanıdır. Ve bu nedenle MAVA kopolimeri ile her biri biyolojik etkiye sahip 5 farklı kopolimer/ilaç konjugatı (MAVA/NA, MAVA/DX, MAVA/HX, MAVA/CF ve MAVA/PT) sentezlenmiştir.

\section{Antitumor, Sitotoksik ve Antimikrobiyel Etki}

Sentezlenen kopolimer/ilaç konjugatlarından MAVA/NA, MAST/PH, MAVA/DX, MAVA/PT ve MAVA/HX sağlıklı fare fibroblast hücre serisi (L929) ve laktat dehidrogenaz $(\mathrm{LDH}))$ üzerine toksik değildir. Antikanser etkiye sahip olduğu bilinen $\mathrm{PH}, \mathrm{DX}, \mathrm{PT}, \mathrm{CF}$ ve HX etken maddeleri ile sentezlenen MAST/PH, MAVA/DX, MAVA/PT, MAVA/CF ve MAVA/HX konjugatlar1; C6 ve HeLa kanser hücreleri üzerinde antitumor etkiye sahiptir $(13,16,17)$. Yalnızca MAAA/AF konjugatının antimikrobiyal testleri yapılmış olup Enterecoccus faecium, Enterohaemorrhagic Escherichia coli (EHEC), Staphylococcus aureus and Listeria monocytogenes suşları üzerinde antimikrobiyel aktiviteye sahip olduğu gösterilmiştir (13-15).

\section{SONUÇ}

$\mathrm{Bu}$ çalışmada daha önceden sentezlene 5 farklı kopolimerin halka açılma tepkimesiyle amin türevi olan farklı ilaç etken maddeleri ile konjugasyonu kıyaslanmıştır. MAVA kopolimeri konjugasyon için en uygun kopolimer seçilmiş olup, konjugatların herhangi bir biyolojik etki gösterip göstermediği de gözönünde bulundurulmuştur. Herbir kopolimer/ilaç ikilisinin içerdiği ilaç etken maddesinin asıl biyolojik etkisi gözönünde bulundurularak yapılan biyolojik etki testlerinde antikanser ilaç içeren konjugatların da aynı zamanda antikanser etkiye sahip olduğu görülmüştür. Sonuç olarak kopolimer/ilaç ikililerinin gösterdiği biyolojik etkinin, konjugatın içerdiği ilaç etken maddesinin sahip olduğu etki ile orantılı olduğu söylenebilir.

\section{TEŞEKKÜR}

$\mathrm{Bu}$ çalışma Cumhuriyet Üniversitesi Bilimsel Araştırma Projeleri (CUBAP) tarafından desteklenmiştir (Proje No: F258 ve F339). 


\section{Derivatization of Some Maleic Anhydride Containing Copolymers with Amine Functionalized Pharmaceutical Active Substances, Structural Characterizations and Biological Activities}

\section{ABSTRACT}

Poly(maleic anhydride-co-styrene) (MAST), poly(maleic anhydride-co-vinyl acetate) (MAVA), poly(maleic anhydride-co-methyl methacrylate) (MAMMA), poly(maleic anhydride-co-allyl phenyl ether) (MAAFE) and poly(maleic anhydride-alt-acrylic acid) (MAAA) copolymers were synthesized by free radical chain polymerization reaction. Modification/derivatization of the copolymers with active pharmaceutical ingredients, in amine form $\left(-\mathrm{NH}_{2}\right)$, was performed by the ring opening reaction. Structural characterization of the copolymers and the conjugated products was carried out by Fourier Transform Infrared (FTIR) and Nuclear Magnetic Resonance (1H-NMR). The FTIR and ${ }^{1} \mathrm{H}-\mathrm{NMR}$ spectra, confirmed that pharmaceutically active agents were covalently bonded to the MAVA copolymer in a succesfull manner. Furthermore cytotoxicity on healthy fibroblast cell lines, antiproliferative activity on cancer cell lines and antibacterial activity on bacterial strains were also investigated in-vitro for synthesized conjugates. MAVA copolymer was also selected the most suitable carrier for modification/derivaritization process by comparing its affinity to the pharmaceutically active agents.

Keywords: Copolymer modification, ring opening reaction, antiproliferative activity, antibacterial activity, structural characterization.

\section{KAYNAKLAR}

1. Popescu I, Suflet DM, Pelin IM, Chitanu GC. Biomedical applications of maleic anhydride copolymers. Rev Roum Chim 2011;56: 173-88.

2. Saad GR, Morsi RE, Mohammady SZ, Elsabee MZ. Dielectric relaxation of monoesters based poly(styrene-co-maleic anhydride) copolymer. J Polym Res 2008;15: 115-23.

3. Atıcı OG, Akar A, Rahimian R. Modification of poly(maleic anhydride-co- styrene) with hydroxyl containing compounds. Turk J Chem 2001;25:259-66.

4. Patel H, Raval DA, Madamwar D, Patel SR. Polymeric prodrug: Synthesis, release study and antimicrobial property of poly(styrene-co-maleic anhydride)-bound acriflavine. Angew Makromol Chem 1998;263: 25-30.

5. Liu HY, Cao K, Yao Z, Li BG, Hu GH. Variations of the glasstransition temperature in the imidization of poly(styrene-comaleic anhydride). J Appl Polym Sci 2007;104: 2418-22.

6. Ringsdorf H. Structure and properties of pharmacologically active polymers. J Polymer Sci 1975;51: 135-53.

7. Duncan R. Polymer conjugates for tumour targeting and intracytoplasmic delivery. The EPR effect as a common gateway? Res Focus Rev 1999;2: 441-9.

8. Breslow DS. Biologically active synthetic polymers. Pure Appl Chem 1976;46: 103-13.

9. Dhal PK, Holmes-Farley SR, Huval CC, Jozefiak TH. Polymers as drugs. Adv Polym Sci 2006;192: 9-58.

10. Duncan R. The dawning era of polymer therapeutics. Nat Rev Drug Discov 2003;2: 347-60.
11. Greish K, Sawa T, Fang J, Akaika T, Maeda H. SMAdoxorubicin, a new polymeric micellar drug for effective targeting to solid tumors. J Control Release 2004;97: 219-30.

12. Karakus G, Zengin HB, Akin Polat Z, Yenidunya AF, Aydin S. Cytotoxicity of three maleic anhydride copolymers and common solvents used for polymer solvation. Polym Bull 2013; 70:1519-1612.

13. Karakus G, Akin Polat Z, Sahin Yaglioglu A, Karahan M, Yenidunya AF. Synthesis, characterization, and assessment of cytotoxic, antiproliferative, and antiangiogenic effects of a novel procainamide hydrochloride-poly(maleic anhydride-costyrene) conjugate. J Biomat Sci-Polym E 2013;24: 1260-76.

14. Karakus G, Akin Polat Z, Yenidunya AF, Zengin HB, Karakus CB. Synthesis, characterization and cytotoxicity of novel modified poly[(maleic anhydride)-co-(vinyl acetate)]/ noradrenaline conjugate. Polym Int 2013;62: 492-500.

15. Kaplan-Can H, Karakus G, Tuzcu N. Synthesis, characterization and in vitro antibacterial assessments of a novel modified poly[maleic anhydride-alt-acrylic acid]/ acriflavine conjugate. Polym Bull 2014;71: 2903-21.

16. Karakus G, Sahin Yaglioglu A, Zengin HB, Karakus CB. Synthesis, characterization and antiproliferative activities of novel modified poly (maleic anhydride-co-vinyl acetate)/ cytosine $\beta$-darabinofuranoside hydrochloride conjugate. Marmara Pharm J 2015;19: 73-81.

17. Karakus, G. Bazı Maleik Anhidrit Kopolimerlerinin Antineoplastik Ajanlarla Türevlendirilmesi ve Karakterizasyonu, Doktora Tezi, Cumhuriyet Üniversitesi Fen Bilimleri Enstitüsü, Sivas; 2010. 